\title{
Zoonotic Alphaviruses in Fatal and Neurologic Infections in Wildlife and Nonequine Domestic Animals, South Africa
}

\author{
Jumari Steyn, Isabel Fourie, Johan Steyl, June Williams, Voula Stivaktas, \\ Elizabeth Botha, Stefanie van Niekerk, Bjorn Reininghaus, Marietjie Venter
}

\begin{abstract}
Alphaviruses from Africa, such as Middelburg virus (MIDV), and Sindbis virus (SINV), were detected in horses with neurologic disease in South Africa, but their host ranges remain unknown. We investigated the contribution of alphaviruses to neurologic infections and death in wildlife and domestic animals in this country. During 20102018, a total of 608 clinical samples from wildlife and nonequine domestic animals that had febrile, neurologic signs or unexplained deaths were tested for alphaviruses. We identified 32 (5.5\%) of 608 alphavirus infections (9 SINV and 23 MIDV), mostly in neurotissue of wildlife, domestic animals, and birds. Phylogenetic analysis of the RNA-dependent RNA polymerase gene confirmed either SINV or MIDV. This study implicates MIDV and SINV as potential causes of neurologic disease in wildlife and nonequine domestic species in Africa and suggests a wide host range and pathogenic potential.
\end{abstract}

lphaviruses (family Togaviridae) have been recAlognized as major emerging viruses. New World alphaviruses, such as Western equine encephalitis virus, Eastern equine encephalitis virus, and Venezuelan equine encephalitis virus, are traditionally associated with severe disease, such as encephalitis and a high mortality rate in humans and horses in the Americas and Australia $(1,2)$. Old World alphaviruses, such as o'nyong nyong virus, chikungunya virus, and Sindbis virus (SINV), are associated mostly with arthralgia, although rare infections with neurologic disease have been reported in humans and equids (3). Chikungunya virus was responsible for millions of human infections in new territories, and although

Author affiliation: University of Pretoria, Pretoria, South Africa (J. Steyn, I. Fourie, J. Steyl, J. Williams, V. Stivaktas, E. Botha, S. van Niekerk, M. Venter); Mpumalanga Veterinary Services, Middelburg, South Africa (B. Reininghaus)

DOI: https://doi.org/10.3201/eid2606.191179 the case-fatality rate was low, outbreaks resulted in major illness and long-term sequelae in affected persons $(4,5)$. Old and New World alphaviruses cluster in separate phylogenetic groups (6), but limited information is available about pathogenesis and host range of alphaviruses from Africa and pathogenesis in animals.

SINV is a human pathogen that is distributed across Africa, Europe, Australia, and Asia (7). Large outbreaks of infection have been recorded in humans in South Africa since 1974 (8). Limited studies on the disease potential of SINV in animals have been conducted. The reservoir hosts are primarily migratory birds $(9,10)$; various Culex mosquitoes are the main vectors. Recent reports suggest that SINV might cause febrile and neurologic disease in horses in South Africa (11,12).

Middelburg virus (MIDV) was discovered in the late 1950s in Aedes species mosquitoes (13), although it was only linked to disease in 1990 (14) after MIDV was isolated from a horse with signs of infection with African horse sickness virus in Zimbabwe (14). Since that time, MIDV has been implicated as the etiologic agent of neurologic and febrile disease in horses in South Africa (11). Seroprevalence studies in South Africa during 1959-1960 identified MIDV antibodies in humans, cattle, sheep, and goats $(15,16)$. The vector status of MIDV is largely unknown; only Ae. caballus and Mansonia africana mosquitoes have been implicated (17). Little is known about the epidemiology of MIDV, including confirmed reservoir hosts, susceptible species, and zoonotic potential. MIDV, recombinant virus originating from Semliki Forest virus and Mayaro virus (14), forms its own complex, rather than clustering within the Semliki Forest virus complex (6).

Identification of MIDV and SINV as possible neurologic pathogens in horses in South Africa prompted 
the investigation of undiagnosed neurologic and febrile disease or sudden unexplained death in wildlife, nonequine domestic animals, and birds. The purpose of our study was to investigate the host range and association of alphaviruses from Africa with neurologic disease and death, as well as to increase knowledge on pathogenesis and the zoonotic potential of these 2 viruses.

\section{Materials and Methods}

\section{Clinical Infections}

This study forms part of an ongoing passive surveillance study to detect zoonotic arboviruses in South Africa. A total of 608 EDTA-treated blood or postmortem specimens from animal species other than horses that had neurologic disease, acute febrile illness of unknown origin, or sudden unexpected death during February 2010-September 2018 in South Africa were submitted to the Centre for Viral Zoonoses, Department of Medical Virology, University of Pretoria (Pretoria, South Africa). Clinical cases were submitted by wildlife veterinarians and pathologists who identified cases that fit the case definition of febrile or neurologic signs or sudden unexpected deaths of unknown origin. EDTA-treated blood or serum samples were submitted when animals were alive, whereas tissues were submitted if the animal died. Preferred tissue type was brain matter or spinal cord and visceral organs, including lungs, spleen, and liver samples. The study was approved under Section 20 (no. 12/11/1/1) by the Department of Forestry and Fisheries and by the Animal Ethics Committee (no. V057-15 and H12/16).

We performed full necropsy examination at the Section of Pathology, Department of Paraclinical Sciences, Faculty of Veterinary Science, University of Pretoria, for animals that had clinically progressive quadriparesis, apparently normal mentation, and positive results for MIDV or SINV by reverse transcription PCR. We collected a wide range of organs and tissues from all wildlife cases and preserved the samples in 10\% neutral buffered formalin for histologic examination. We microscopically examined routinely prepared, hematoxylin and eosin-stained (18) histologic sections by using a standard light microscope.

\section{RNA Extraction and PCR}

We extracted all specimens under Biosafety Level 3 (BSL-3) conditions in the Department of Forestry and Fisheries compliant BSL-3 laboratory at the Centre for Viral Zoonoses, University of Pretoria. We extracted virus RNA from blood or body fluids by using a Viral Mini Kit (QIAGEN, https://www.qiagen.com) according to the manufacturer's instructions and virus RNA from tissue samples by using the RNeasy Kit (QIAGEN). We analyzed all clinical specimens by using genus-specific nested real-time PCRs (11). We designed specific MIDV (forward ${ }^{6285} 5^{\prime}-$ GCAGCCTTTTGTCCGTCYAA-236305 and reverse ${ }^{66335}$ '-GGCTTCAAGTCRTAGGTTT-3'6614) and SINV (forward 62855'-GCAACCTTYTGCCCCGCYAA-'36305 and reverse ${ }^{6633} 5^{\prime}$-GGGACCAAATTATRCGTCT-326613) nested primers to increase the RNA-dependent RNA polymerase gene region from $198 \mathrm{bp}$ to $348 \mathrm{bp}$ for phylogenetic analysis by using the same conditions as in the alphavirus PCR (11). We designed primers on the basis of MIDV strain SAE_25/11 (GenBank accession no. KF680222) and SINV strain SA_AR86 (accession no. U38305). For differential diagnosis, we also screened all specimens for flaviviruses (19), equine encephalosis virus (20), and Shuni virus (21).

\section{Sanger Sequencing and Phylogenetic Analysis}

Arbovirus PCR-positive results were confirmed by sequencing at Inqaba Biotec (https:/ / www.inqababiotec. co.za). We analyzed sequence data by using CLC Main Workbench 8 (QIAGEN) and MEGA 6.06 software (https:/ / www.megasoftware.net). We performed multiple sequence alignments by using MAFFT version 7 software (http://mafft.cbrc.jp) with default parameters and used them to assemble sequences. We conducted maximum-likelihood analysis by using RaxML (22) and invoking the auto-MRE bootstopping function by applying a generalized time-reversible model with gamma distribution of rates across sites. We calculated bootstrap support values by using the autoMRE bootstopping criterion in RaxML. We conducted P-distance analysis in MEGA 6.06 and determined average within mean group distance between MIDV and SINV strains. We submitted sequences $>200$ bp to GenBank.

\section{Virus Isolation}

We subjected all PCR-positive samples to virus isolation on African green monkey kidney cells (Vero) and baby hamster kidney cells (BHK-21 clone 3). We maintained cells in Earle minimum essential medium (EMEM) containing L-glutamine (Lonza, https://www.lonza.com), MycoZap CL-Plus (Lon$\mathrm{za}), 10 \%$ fetal calf serum (FCS) (Lonza) for Vero or $20 \%$ FCS for BHK-21 clone 3 cells in an Intercool Incubator (Lasec, https://www.lasec.com) at $37^{\circ} \mathrm{C}$ and an atmosphere of $5.0 \% \mathrm{CO}_{2}$.

We performed isolations by using EMEM containing $10 \%$ fetal calf serum and Mycozap CL-Plus for 
Vero cells and $20 \%$ fetal calf serum and Mycozap CLPlus for BHK-21 clone 3 cells and incubated at $37^{\circ} \mathrm{C}$ in an atmosphere of $5 \% \mathrm{CO}_{2}$. We inoculated blood or serum samples $(200 \mu \mathrm{L})$ from animals directly onto phosphate-buffered saline (PBS)-washed cells, incubated for $1 \mathrm{~h}$, and washed once with PBS, then added $2 \%$ EMEM. We cut tissue specimens into pieces $(\approx 5$ $\mathrm{mg}$ ) and homogenized with sterile glass beads (Merck, https://www.merck.com) at $100 \times g$ for $6 \mathrm{~min}$ by using a TissueLyzer (QIAGEN). We then centrifuged homogenates at $1,000 \times g$ for $10 \mathrm{~min}$ to collect debris. We used $200 \mu \mathrm{L}$ of supernatant to infect PBSwashed cells, incubated them for $1 \mathrm{~h}$, and then added 2\% EMEM. We passaged cultures 3-4 times at 7-day intervals, observing monolayers daily for cytopathic effect. Between passages, we froze cultures at $-80^{\circ} \mathrm{C}$, thawed 3 times, and clarified by centrifuging at 1,000 $\times g$ for 5 min.

\section{Data Analysis}

We performed data and statistical analyses by using Epi Info version 7.2.0.1 (https://www.cdc.gov/ epiinfo/index.html) and a Fisher exact test with 95\% CIs and odds ratios (ORs) to calculate the association between clinical signs and infection. We excluded animals that were found dead $(\mathrm{n}=76)$ or were aborted $(n=23)$ or stillborn $(n=13)$ from OR analysis.

\section{Results}

During the 9-year study period, we tested 608 animals that had unsolved neurologic, febrile, and respiratory signs or sudden unexpected death. We detected MIDV in 23 (3.8\%, 95\% CI 2.4\%-5.5\%) animals and SINV in $9(1.5 \%, 95 \%$ CI $0.5 \%-2.4 \%)$ (Table $1)$. We detected MIDV in wildlife (16/361; $4.4 \%, 95 \%$ CI $2.3 \%-6.6 \%)$, domestic animals $(5 / 196 ; 2.6 \%, 95 \%$ CI $0.3 \%-4.8 \%)$, and wild birds $(2 / 51 ; 3.9 \%, 95 \%$ CI $0 \%-9.3 \%)$ and SINV in wildlife $(7 / 608 ; 1.1 \%, 95 \%$ CI $0.5 \%-3.4 \%)$ and domestic animals $(2 / 196 ; 1 \%, 95 \%$ CI $0 \%-2.4 \%$ ) (Table 1 ). We did not detect SINV in clinical samples from birds.

The 608 animals tested were from 99 animal species, of which 14 species were positive for MIDV or SINV (Table 1). We detected MIDV in white rhinoceros $(9.2 \%, 95 \%$ CI $2.2 \%-16.3 \%)$, buffalo $(3.7 \%, 95 \%$ CI $0 \%-$ $8.7 \%)$, domestic bovids (5.4\%, 95\% CI 0.8\%-10.0\%), warthogs $(7.7 \%, 95 \%$ CI $0 \%-18.0 \%)$, lions $(22.2 \%, 95 \%$ CI $0 \%-49.4 \%$ ), birds (lemon dove and blue crane; $3.9 \%, 95 \%$ CI $0 \%-9.2 \%)$, sable antelopes $(3.8 \%, 95 \%$ CI $0 \%-8.9 \%)$, waterbucks $(33.3 \%, 95 \%$ CI $0 \%-86.7 \%)$,

\begin{tabular}{|c|c|c|c|}
\hline \multirow[b]{2}{*}{ Animal } & \multirow[b]{2}{*}{ No. tested } & \multicolumn{2}{|c|}{ No. positive $(\%, 95 \% \mathrm{Cl})$} \\
\hline & & MIDV & SINV \\
\hline Buffalo (Syncerus caffra) & 54 & $2(3.7,0.0-8.7)$ & $1(1.9,0.0-5.4)$ \\
\hline Aviant & 51 & $2(3.9,0.0-9.2)$ & 0 \\
\hline Sable antelope (Hippotragus niger) & 53 & $2(3.8,0.0-8.9)$ & $2(3.8,0.0-8.9)$ \\
\hline Warthog (Phaecocherus africanus) & 26 & $2(7.7,0.0-18.0)$ & 0 \\
\hline White rhinoceros (Ceratotherium simum) & 65 & $6(9.2,2.2-16.3)$ & $1(1.5,0.0-4.5)$ \\
\hline Lion (Panthera leo) & 9 & $2(22.2,0.0-49.4)$ & 0 \\
\hline Waterbuck (Kobus ellipsiprymnus) & 3 & $1(33.3,0.0-86.7)$ & 0 \\
\hline Genet (Genetta genetta) & 2 & $1(50.0,0.0-119.3)$ & $1(50.0,0.0-119.3)$ \\
\hline Giraffe (Giraffa camelopardalis) & 6 & 0 & $1(16.7,0.0-46.5)$ \\
\hline Blesbuck (Damaliscus pygargus phillipsi) & 4 & 0 & $1(25.0,0.0-67.4)$ \\
\hline Crocodile (Crocodylus niloticus) & 12 & 0 & 0 \\
\hline Springbok (Antidorcas marsupialis) & 4 & 0 & 0 \\
\hline Roan antelope (Hippotragus equinus) & 3 & 0 & 0 \\
\hline Other antelope $\ddagger$ & 82 & 0 & 0 \\
\hline Elephant (Loxodonta africana) & 6 & 0 & 0 \\
\hline Equine (zebra/donkeys)§ & 10 & 0 & 0 \\
\hline Carnivoresף & 17 & 0 & 0 \\
\hline Alpaca & 8 & 0 & 0 \\
\hline Domestic bovid & 93 & $5(5.4,0.8-10.0)$ & 0 \\
\hline Domestic sheep & 45 & 0 & $1(2.2,0.0-6.5)$ \\
\hline Domestic and other porcine & 5 & 0 & $1(20.0,0.0-46.5)$ \\
\hline Camel & 8 & 0 & 0 \\
\hline Goat & 1 & 0 & 0 \\
\hline Wildlife & 361 & $16(4.4,2.3-6.6)$ & $7(1.9,0.5-3.4)$ \\
\hline Domestic & 196 & $5(2.6,0.3-4.8)$ & $2(1.0,0.0-2.4)$ \\
\hline Avian & 51 & $2(3.9,0.0-9.2)$ & 0 \\
\hline Total & 608 & $23(3.8,2.4-5.5)$ & $9(1.5,0.5-2.4)$ \\
\hline
\end{tabular}

${ }^{*}$ MIDV, Middelburg virus; SINV, Sindbis virus.

†Avian MIDV-positive: laughing dove (Spilopelia senegalensis) and blue crane (Grus paradisea).

‡Kudu, wildebeest, impala.

$\S Z$ Zebra and donkeys.

ПJackal, hyena, wild dog, civet. 
and genets $(50 \%, 95 \%$ CI 0\%-119.3\%) (Table 1$)$. SINV was detected in buffalo $(1.9 \%, 95 \%$ CI $0 \%-5.4 \%)$, sable antelopes $(3.8 \%, 95 \%$ CI $0 \%-8.9 \%)$, rhinoceroses $(1.5 \%, 95 \%$ CI $0 \%-4.5 \%)$, giraffes $(16.7 \%, 95 \%$ CI $0 \%-$ 46.5), European wild boar (16.7\%, 95\% CI 0\%-46.5\%), sheep $(2.2 \%, 95 \%$ CI $0 \%-6.5 \%)$, blesbucks $(25 \%, 95 \%$ CI $0 \%-67.4 \%)$, and genets $(50 \%, 95 \%$ CI $0 \%-119.3 \%)$ (Table 1). One co-infection with MIDV and SINV was reported in a genet (Table 1). Two white rhinoceroses had co-infections (MVA07/10 with MIDV and Shuni virus, MVA11/10 with MIDV and equine encephalosis virus). Two animals, a domestic bovid (ZRU176/14/2) and a buffalo (ZRU160/18), had coinfections with MIDV and West Nile virus.

All SINV-positive animals and $20(87 \%)$ of 23 MIDV PCR-positive animals had virus detected in postmortem specimens (Table 2). MIDV was detected primarily in the central nervous system (CNS; $14 / 23,60.9 \%)$, followed by visceral organs (10/23,
$43.5 \%)$, blood $(5 / 23,21.7 \%)$, and respiratory organs $(2 / 23,8.7 \%)$. SINV was detected primarily in the CNS $(5 / 9,55.6 \%)$, visceral organs $(3 / 9,33.3 \%)$, respiratory organs $(2 / 9,22.2 \%)$ and cerebrospinal fluid $(1 / 9$, $11.1 \%)$. All clinically sick animals infected with MIDV $(22 / 22)(p=0.06)$ and SINV $(6 / 6)(p=1)$ had neurologic manifestations as a primary diagnostic sign (Table 2). Tongue paralysis (OR 32.5, 95\% CI 2.9-368.3) was associated with SINV-positive animals $(p<0.05)$ (Table 2). Three animals were found dead and subsequently found to be positive for MIDV (waterbuck) and SINV (buffalo and blesbuck), and an aborted Merino sheep fetus was positive for SINV (Table 2).

Most MIDV infections were reported during 2010 $(5 / 62,8.1 \%)$ and $2015(5 / 60,8.3 \%)$, followed by 2017 $(4 / 90,4.4 \%), 2014(3 / 69,4.3 \%), 2018$ (3/75, 4.0\%), $2012(1 / 30,3.3 \%)$, and $2011(2 / 80,2.5 \%)$. No MIDV infections were detected during 2016 (Figure 1). SINV infections were highest in 2018 (4/75, 5.3\%), followed

\begin{tabular}{|c|c|c|c|c|}
\hline Virus, sign, and outcome & No. (\%) positive, $\mathrm{n}=22$ & No (\%) negative, $\mathrm{n}=474$ & Odds ratio $(95 \% \mathrm{Cl})$ & $p$ value \\
\hline \multicolumn{5}{|l|}{ MIDV } \\
\hline \multicolumn{5}{|l|}{ Sign } \\
\hline Fever & 4 (18.2) & $42(8.9)$ & $2.3(0.7-7.1)$ & 0.1 \\
\hline Neurologic signs & $22(100.0)$ & $404(85.2)$ & ND & 0.06 \\
\hline Ataxia & $4(18.2)$ & $100(21.1)$ & $0.8(0.2-2.5)$ & 1.0 \\
\hline Paralysis & $4(18.2)$ & $60(12.7)$ & $1.5(0.5-4.7)$ & 0.7 \\
\hline Quadriparesis & $6(27.3)$ & $114(24.1)$ & $1.8(0.5-3.1)$ & 0.8 \\
\hline Tongue paralysis & 0 & $4(0.8)$ & ND & 1.0 \\
\hline Recumbency & $4(18.2)$ & $101(21.3)$ & $0.8(0.3-2.5)$ & 1.0 \\
\hline Dyspnea & 0 & $81(17.1)$ & ND & 1.0 \\
\hline Hemorrhage & 0 & $11(2.3)$ & ND & 1.0 \\
\hline Congenital deformities & 0 & $7(1.5)$ & ND & 1.0 \\
\hline Blindness & 0 & $11(2.3)$ & ND & 1.0 \\
\hline Icterus & 0 & $2(0.4)$ & ND & 1.0 \\
\hline Seizure & 0 & $29(6.1)$ & ND & 1.0 \\
\hline Outcome & $\mathrm{n}=23$ & $\mathrm{n}=585$ & & \\
\hline Sudden unexpected death & $1(4.4)$ & $75(12.8)$ & $0.3(0.0-2.3)$ & 0.3 \\
\hline Abortion & 0 & $23(4.1)$ & ND & 1.0 \\
\hline Stillbirth & 0 & $13(2.7)$ & ND & 1.0 \\
\hline Fatal & $20(87.0)$ & $501(85.6)$ & $1.1(0.3-3.9)$ & 1.0 \\
\hline SINV & $\mathrm{n}=6$ & $n=490$ & & \\
\hline \multicolumn{5}{|l|}{ Sign } \\
\hline Fever & $1(16.7)$ & $45(9.2)$ & $2.0(0.2-17.3)$ & 0.5 \\
\hline Neurologic signs & $6(100.0)$ & $420(85.7)$ & ND & 1.0 \\
\hline Ataxia & $2(33.3)$ & $102(20.8)$ & $1.9(0.3-10.5)$ & 0.6 \\
\hline Paralysis & $1(16.7)$ & $63(12.9)$ & $1.4(0.2-11.8)$ & 0.7 \\
\hline Quadriparesis & 0 & $120(24.5)$ & ND & 1.0 \\
\hline Tongue paralysis & $1(16.7)$ & $3(0.6)$ & $32.5(2.9-368.3)$ & $<0.05$ \\
\hline Recumbency & $2(33.3)$ & $103(21.0)$ & $1.9(0.3-10.4)$ & 0.6 \\
\hline Dyspnea & $1(16.7)$ & $80(16.3)$ & $1.0(0.1-89)$ & 1.0 \\
\hline Hemorrhage & 0 & $11(2.2)$ & ND & 1.0 \\
\hline Congenital deformities & 0 & $7(1.4)$ & ND & 1.0 \\
\hline Blindness & 0 & $11(2.4)$ & ND & 1.0 \\
\hline Icterus & 0 & $2(0.4)$ & ND & 1.0 \\
\hline Seizure & 0 & $29(5.9)$ & ND & 1.0 \\
\hline Outcome & $\mathrm{n}=9$ & $\mathrm{n}=599$ & & \\
\hline Sudden unexpected death & $2(22.2)$ & $74(12.7)$ & $0.5(0.1-2.4)$ & 0.3 \\
\hline Abortion & $1(11.1)$ & $22(3.8)$ & $3.3(0.4-27.4)$ & 0.3 \\
\hline Stillbirth & 0 & $13(2.7)$ & ND & 0.8 \\
\hline Fatal & $9(100.0)$ & $512(85.5)$ & ND & 1.0 \\
\hline
\end{tabular}

${ }^{*} \mathrm{ND}$, not determined; MIDV, Middelburg virus; SINV, Sindbis virus. 
by $2014(2 / 69,2.9 \%), 2013(1 / 50,2 \%)$, and 2010 and 2015 (each 1/67, 1.5\%). No SINV infections were reported during 2011, 2012, 2016, and 2017 (Figure 1). MIDV positivity was highest in April (5/55, 9.1\%), followed by November (3/38, 7.9\%) (Figure 1). No positive animals were reported during February, October, or December. SINV positivity was highest in September $(3 / 65,4.6 \%)$, followed by February $(2 / 48$, $4.2 \%$ ) (Figure 1). Samples were received from all 9 provinces, although positive samples were detected in only 6 provinces (Figure 2).

No specific macroscopic lesions could be demonstrated at necropsy for cases submitted to the Section of Pathology, Faculty of Veterinary Science, University of Pretoria. Similar to other parenchymal tissues examined, no distinct cytologic nor architectural abnormalities could be demonstrated in the CNS of examined cases. Some of these animals died after a short period ( $<3$ days) of recumbency. In these cases, secondary factors, such as dehydration and unrelenting high levels of stress, were suspected to contribute to death. In some instances, animals with severe cases were euthanized for humane reasons or as part of disease management for elective necropsy to determine the cause of outbreaks of neurologic signs in wildlife.

Phylogenetic analysis of the partial nonstructural protein 4 (nsP4) gene region (348 bp) confirmed all virus-positives cases as being infected with MIDV or SINV (Figure 3). Maximum-likelihood analysis resulted in a topology lacking strong support in deeper nodes for several alphavirus groups. However, we obtained bootstrapping values of 95 for MIDV clades and 93 for SINV clades (Figure 3). The MIDV complex had 2 separate clades within the group, and viruses detected in lions (Carnivora) were sister clades to viruses detected in rhinoceroses, warthogs, buffalo, sable antelopes, domestic bovids, and blue cranes, which clustered together (bootstrap value $=70)($ Figure 3 ) and had a between-group

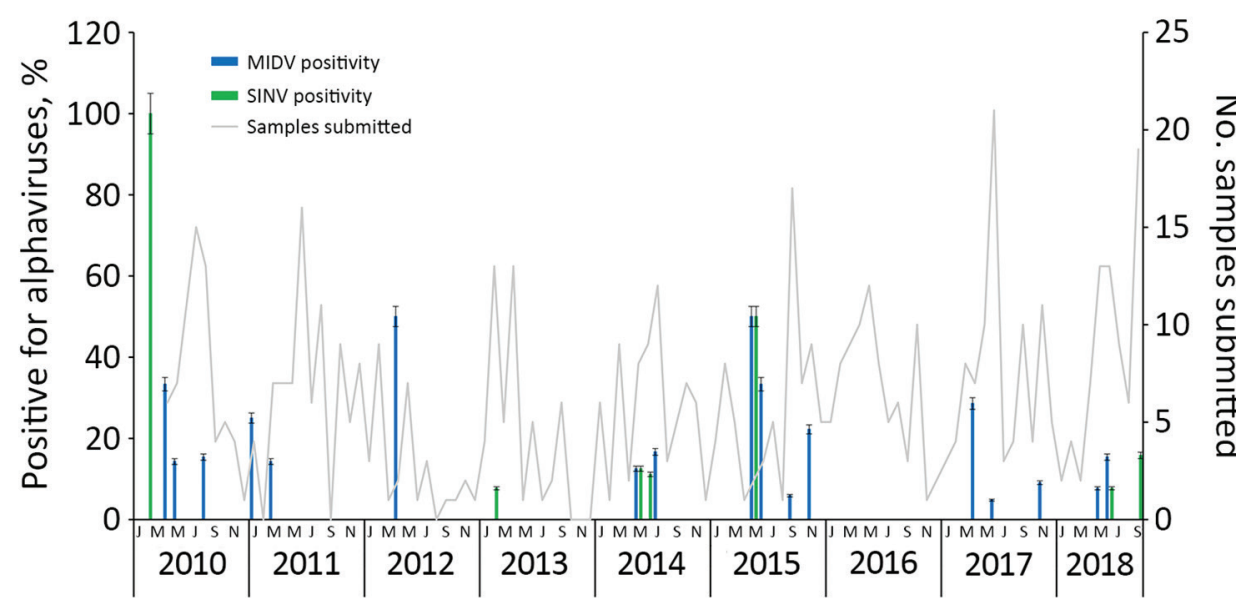

mean distance of $96 \%$. The SINV clade (Western equine encephalitis virus complex) also formed a separate cluster with the positive samples primarily from the 2018 group that was separate from positive samples reported in 2010, 2013, and 2014 (bootstrap value = 66) (Figure 3 ) and had a between group mean distance of $93.7 \%$. Within-group mean nucleotide distances were $98.4 \%$ for MIDV and $95.4 \%$ for SINV.

\section{Discussion}

We identified a total of 32 alphavirus infections in wildlife, nonequine domestic animals, and 2 birds that had neurologic or febrile signs or unexplained death over a period of 9 years (2010-2018) as MIDV (n $=23)$ or SINV $(n=9)$. Detection of these viruses in the CNS indicates that they are able to cross the bloodbrain barrier and suggests that they might cause pathologic changes, neurologic disease, and death in infected animals. Detection of viral RNA in respiratory organs and visceral organs suggest spread of these viruses throughout the body. The success rate of virus isolation from neural tissue is low because death is often the end stage of disease concurrent with a low virus titer, which can often only be detected by nested PCR. Virus isolation can also be related to the quality of clinical specimens received from wildlife and domestic animals, which were often found dead in remote areas and took some time to reach the laboratory, as compared with equine cases, which are often detected earlier by owners during the stage of clinical disease and therefore are sampled earlier.

All cases were accompanied by a case investigation form with clinical and epidemiologic data recorded by the submitting veterinarian. All animals that had clinical information available had neurologic signs suggesting infection with MIDV and SINV as likely etiologies of neurologic disease $(p=0.06)$ despite the small sample size of alphavirus-positive
Figure 1. Seasonal detection of 32 alphavirus-positive infections of wildlife, nonequine domestic animals and birds, South Africa, February 2010-September 2018. Error bars indicate $95 \%$ Cls. MIDV, Middelburg virus; SINV, Sindbis virus. 


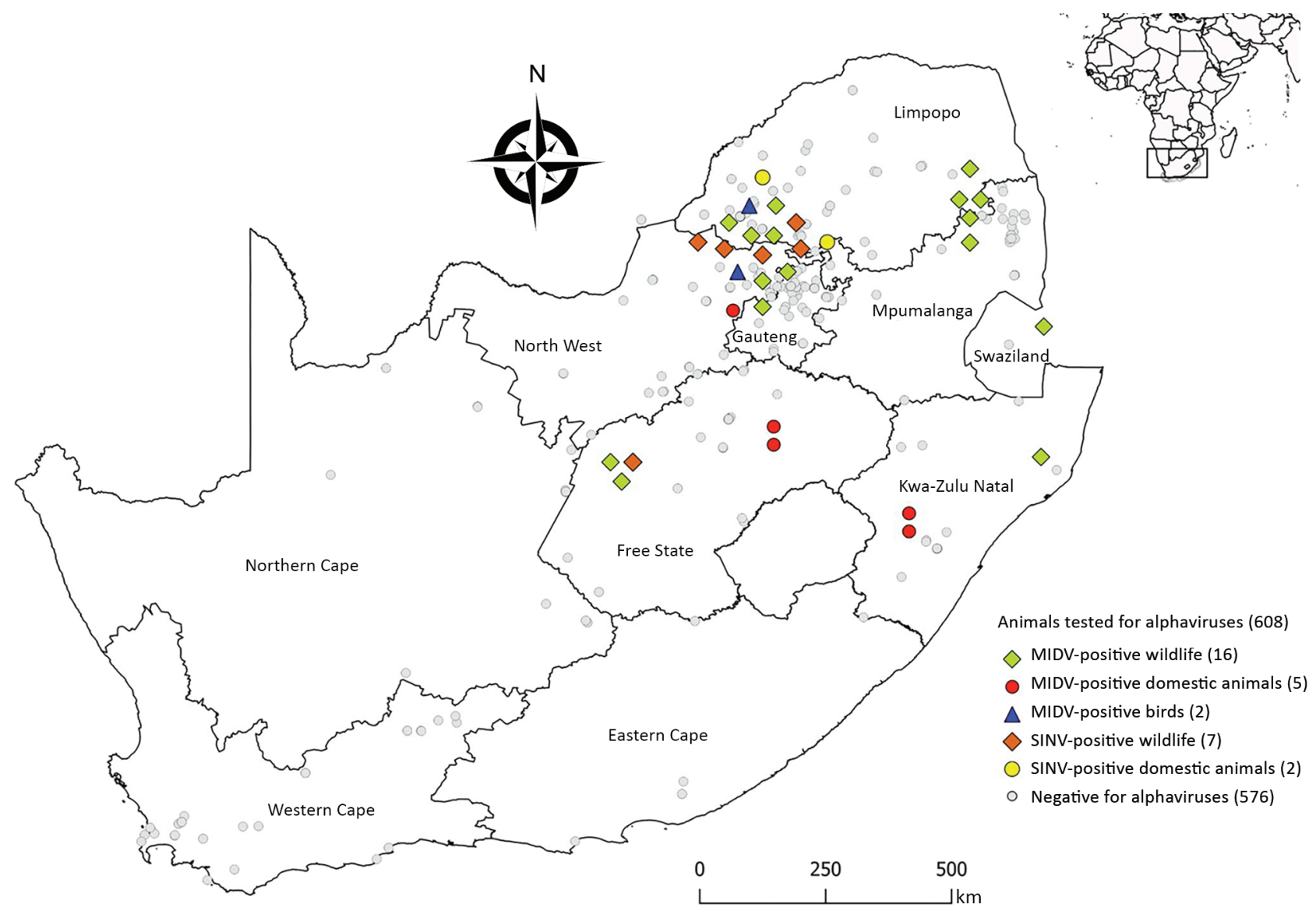

Figure 2. Locations of MIDV and SINV PCR-positive and -negative samples from wildlife, nonequid domestic animals, and avian species, South Africa, 2010-2018. Inset shows location of South Africa in Africa. Values in parentheses are number of animals. MIDV, Middelburg virus; SINV, Sindbis virus.

cases compared with alphavirus-negative cases. None of the other signs could clearly be associated with these viruses because of the small sample size of virus-positive animals. This finding suggests that these Old World alphaviruses might have similar characteristics to their New World relatives in some species $(11,23)$. SINV was strongly associated with tongue paralysis, as observed in the giraffe (ZRU54_13). Although the overall positivity rate was low for samples tested during this study, specific species were positive more frequently for alphaviruses. These species include white rhinoceros, buffalo, and sable antelope, all of which had $\geq 1$ infections for MIDV and SINV.

MIDV was reported more frequently in white rhinoceroses and domestic bovids. SINV was not detected in domestic bovids but was detected in sheep and domestic porcines. In a few instances, samples from an animal were submitted from a cluster of animal deaths and apparent outbreak scenarios. A MIDV-positive white rhinoceros (MVA004/10) was given a diagnosis after 9 rhinoceroses from the same population had similar clinical signs. All animals were subjected to postmortem investigation over a 2-year duration at the Faculty of Veterinary Science, University of Pretoria. CNS tissues from an adult white rhinoceros (MVA007/10) from Broederstroom, North West Province, showed positive results for MIDV and equine encephalosis virus. A rhinoceros calf that was kept in the same boma (livestock enclosure) had similar signs and had died 5 days earlier. A warthog (MVA51/10) was part of a disease outbreak involving $\approx 50$ similar cases in contact animals of the same species in Marekele National Park, Limpopo Province. All warthogs of the specific sounder (group) showed signs of ataxia that lasted 3-7 days, after which some recovered and some died. A captive-bred African buffalo calf from Bloemfontein, Free State Province, also died after paralysis developed, and an uncountable number of animals in the herd were positive for MIDV. These 3 cases of disease can be regarded as disease outbreaks affecting multiple contact animals from the same epizootic unit. 
Phylogenetic analyses based on the partial nsP4 gene support the monophyletic grouping of SINV with the New World viruses in the Western equine encephalitis virus complex $(24,25)$. The analysis also supports the grouping of MIDV strains into a genetic complex, with a $95 \%$ bootstrap support (23), with MIDV sequences obtained from 2 lions (ZRU209_15 and ZRU211_15), forming a sister

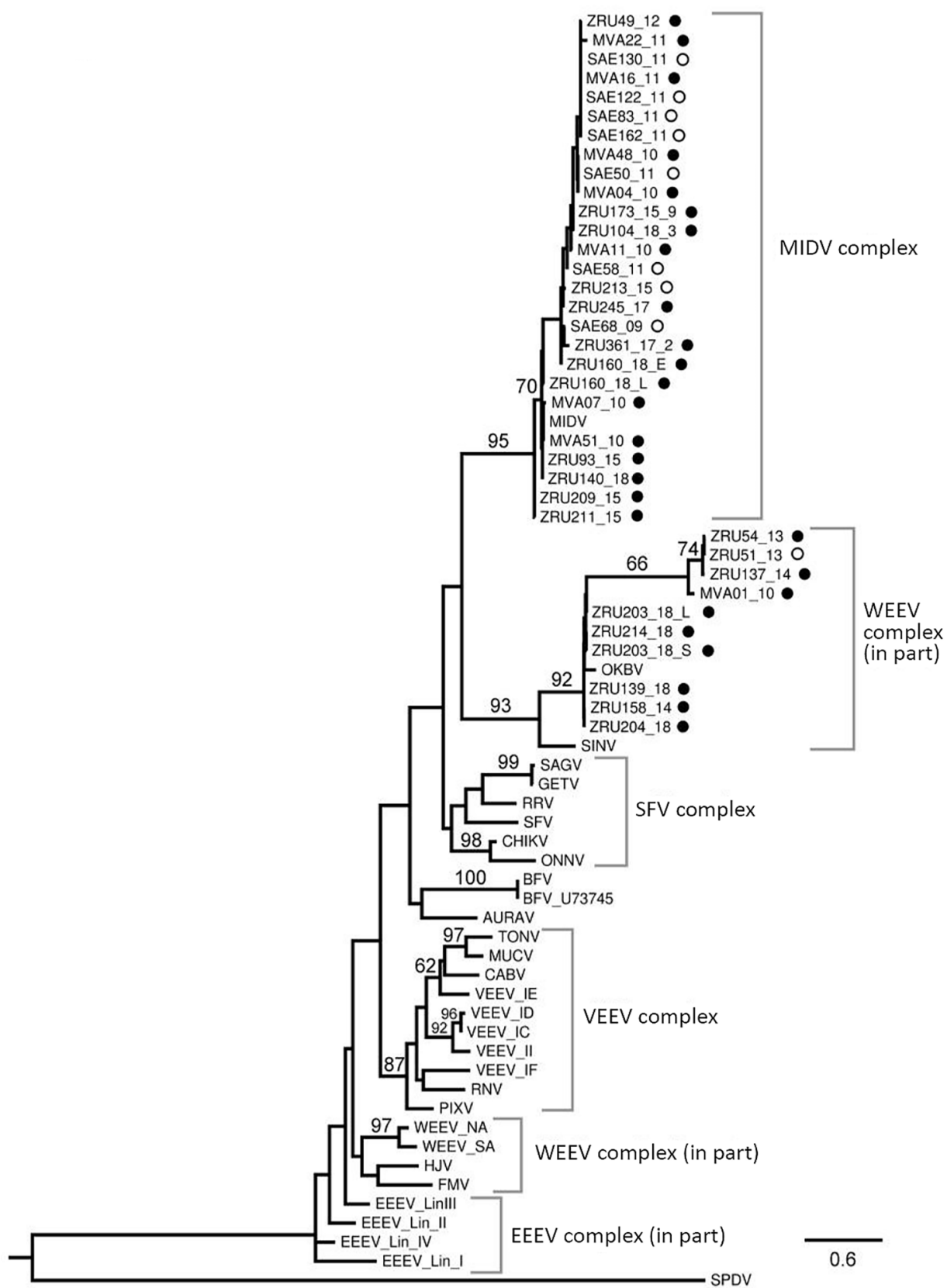

Figure 3. Phylogram of the RNA-dependent RNA polymerase gene (348-bp fragment) of alphaviruses rooted at the midpoint and created by using maximum-likelihood analysis ( 67 taxa, generalized time-reversible model with gamma distribution of rates across sites). Black circles indicate wildlife, domestic animals, and birds from South Africa, February 2010-September 2018, and open circles indicate previously reported virus-positive horses (11). Numbers on branches are bootstrap support values. Values are shown if they are >60. Sample identification and GenBank Accession numbers: MVA51/10, MK114099; ZRU139/18, MK114091; ZRU140/18, MK114087; ZRU158/14, MK114089; ZRU160/18, MK114092, ZRU203/18_Lung, MK114094; ZRU203/18_Spleen, MK114093; ZRU204/18, MK114095; ZRU209/15, MK114096; ZRU211/15, MK114097; ZRU214/18, MK114098; ZRU54/13, MK114090; ZRU93/15, MK114088. Reference strain, name, accession number, and origin are as described by Forrester et al. (6). Scale bar indicates nucleotide substitutions per site. EEEV, Eastern equine encephalitis virus; MIDV, Middelburg virus; SFV, Semliki Forest virus; SPDV, salmon pancreas disease virus; WEEV, Western equine encephalitis virus. 
group to the other virus-positive animals. A mean nucleotide distance of $96 \%$ was observed between the 2 groups. The 2 MIDV-positive lions originated from Mpumalanga Province, and the rest of the MIDV-positive animals were from Gauteng, Limpopo, Free State, Northern Cape, Western Cape, and KwaZulu-Natal Provinces. This clade groups with MIDV strains previously identified in horses from these areas (11). These findings could indicate geographic clustering between strains.

Similar results were obtained for the SINV strains, although positive samples clustered according to year, with a between group mean nucleotide distance of $93.7 \%$, possibly indicating changes in the strains circulating over time. Because birds are believed to be reservoir hosts for SINV, new strains might be introduced through migratory birds. Pdistance analysis showed little or no nucleotide variation in the nsP4 gene region for MIDV and SINV strains respectively identified in this study, apart from the limited differences described above, indicating genetically similar strains. However, this gene segment is highly conserved, and sequence lengths were relatively short (198-348 bp). Attempts to amplify more gene regions, as well as virus isolation, were not successful.

The results of this study demonstrate that alphaviruses might be associated with neurologic disease in wildlife, nonequine domestic animals, and birds in South Africa. Wide geographic distribution of MIDV and SINV in Africa suggests that this distribution should be investigated in other regions. Humans living near wildlife and livestock, such as domestic bovids, sheep, and porcines, might have similar exposure to mosquito vectors and should therefore also be monitored for potential zoonotic infections. SINV has been shown to have birds as its reservoir host and is a well-known human pathogen in South Africa, although most described cases are nonneurologic and associated with febrile disease or arthralgia. Our study identified SINV in neural tissue of various wildlife and nonequine domestic species that had neurologic signs of infection. The geographic range, prevalence of infection in various species, speciesspecific differences, and seroprevalence need to be determined to define the epidemiology of these pathogens. Serologic evidence for MIDV in humans has been demonstrated in South Africa (26), although such evidence is less informative for SINV. This finding might be caused by host range preference and spread of the vectors associated with these viruses.

Reservoir hosts for MIDV are unknown. Our suggestion of a higher prevalence of MIDV relative to SINV warrants further investigation. Widespread distribution of MIDV suggest birds might play a role in the spread of this virus. However, a dove and blue crane were the only virus-positive birds identified, both submitted as postmortem specimens. Further investigation is needed regarding the potential of the identified species to function as reservoir and amplification hosts and potential for transmission of virus to vectors. Spillover of MIDV into humans through adaption to additional vectors should be monitored. Investigation of neurologic cases and deaths in wildlife and domestic animals suggested that most cases occur during January-July - from the second half of the summer months to late autumn or early winter in warmer parts of the country, where many wildlife resideafter which vector numbers usually decrease because of colder winter temperatures.

Future studies into the epidemiology of SINV and especially MIDV would greatly benefit from analysis of increased sample sizes or whole-genome sequencing, combined with serologic analyses of affected species, especially in outbreak investigations. Syndromic surveillance for febrile and neurologic disease in sensitive species might act as an early warning system for outbreaks of emerging and reemerging arboviruses and predict outbreaks in humans $(27,28)$.

A limitation of our study is that all other possible infectious and noninfectious etiologies could not be excluded by comprehensive investigations for all cases, suggesting that the causative link with clinical signs still has to be regarded with caution. Also, serum samples from PCR-positive animals were not available because most animals were tested postmortem, which limited validation by serologic assays for this study. However, use of serum samples should be a focus of future investigations.

Most emerging zoonotic diseases are believed to be caused by pathogens that originate from wildlife (29). Wildlife might either assume the role of reservoir or amplification host with or without clinical disease or be dead end or incidental hosts that might have severe disease $(30,31)$. To our knowledge, MIDV and SINV neurologic infections have not been reported in wildlife and nonequine domestic animals. Our study demonstrated a wide host range for these viruses, and detection of these viruses directly in the neurologic tissue in several cases suggests crossing of the blood-brain barrier and MIDV and SINV as the probable cause of neurologic signs. This finding highlights the need for surveillance of alphaviruses to prevent spillover events and outbreaks in humans. 


\section{Acknowledgments}

We thank all veterinarians and veterinary pathologists across South Africa for submitting samples and Louwtjie Snyman for assisting with phylogenetic analyses. This study was cleared by section $20(12 / 11 / 1 / 1)$ approval through the Department of Agriculture Forestry and Fisheries, by the animal ethics committee (V057-15) (J.S.) and (H12/16) (M.V.) of the University of Pretoria and the PhD research committee. Buffalo samples were transported under a Red Cross permit (LDK2016/9/1) to the BSL3 laboratory.

The study was supported by the US Centers for Disease Control and Prevention Global Disease Detection grant for zoonotic arboviruses (grant no. 1U19GH000571-01-GDD), Non-Research CoAg and National Health Service Laboratory project 23, and University of Pretoria Zoonotic Arbo and Respiratory virus program income-generated funds. J.S. received doctoral scholarships from the National Research Foundation (grant no. 95175), the Meat Industry Trust (grant no. IT8114/98), and the Poliomyelitis Research Foundation (grant no. 15/112), as well as a partial studentship from the US-CDC Cooperative Agreement (no. 5 NU2GGH001874-02-00) with the University of Pretoria.

\section{About the Author}

Dr. Steyn is a virologist at the Centre for Viral Zoonoses, University of Pretoria, Pretoria, South Africa. Her primary research interest is investigating arboviruses with zoonotic potential at human/animal interface areas.

\section{References}

1. Aguilar PV, Estrada-Franco JG, Navarro-Lopez R, Ferro C, Haddow AD, Weaver SC. Endemic Venezuelan equine encephalitis in the Americas: hidden under the dengue umbrella. Future Virol. 2011;6:721-40. https://doi.org/10.2217/fvl.11.50

2. Lambert AJ, Martin DA, Lanciotti RS. Detection of North American eastern and western equine encephalitis viruses by nucleic acid amplification assays. J Clin Microbiol. 2003;41:379_ 85. https://doi.org/10.1128/JCM.41.1.379-385.2003

3. Zacks MA, Paessler S. Encephalitic alphaviruses. Vet Microbiol. 2010;140:281-6. https:/ / doi.org/10.1016/ j.vetmic.2009.08.023

4. Powers AM, Brault AC, Tesh RB, Weaver SC. Re-emergence of chikungunya and O'nyong-nyong viruses: evidence for distinct geographical lineages and distant evolutionary relationships. J Gen Virol. 2000;81:471-9. https:/ / doi.org/ 10.1099/0022-1317-81-2-471

5. Wahid B, Ali A, Rafique S, Idrees M. Global expansion of chikungunya virus: mapping the 64-year history. Int J Infect Dis. 2017;58:69-76. https://doi.org/10.1016/j.ijid.2017.03.006

6. Forrester NL, Palacios G, Tesh RB, Savji N, Guzman H, Sherman M, et al. Genome-scale phylogeny of the alphavirus genus suggests a marine origin. J Virol. 2012;86:2729-38. https://doi.org/10.1128/JVI.05591-11
7. Laine M, Luukkainen R, Toivanen A. Sindbis viruses and other alphaviruses as cause of human arthritic disease. J Intern Med. 2004;256:457-71. https:/ / doi.org/10.1111/ j.1365-2796.2004.01413.x

8. McIntosh B, Jupp P, Dos Santos I, Meenehan G. Epidemics of West Nile and Sindbis viruses in South Africa and Culex (Culex) univittatus. South African Journal of Science. 1976;72:295-300.

9. Lwande OW, Obanda V, Bucht G, Mosomtai G, Otieno V, Ahlm C, et al. Global emergence of Alphaviruses that cause arthritis in humans. Infect Ecol Epidemiol. 2015;5:29853. https:// doi.org/10.3402/iee.v5.29853

10. Burt FJ, Goedhals D, Mathengtheng L. Arboviruses in southern Africa: are we missing something? Future Virol. 2014;9:993-1008. https:// doi.org/10.2217/fvl.14.87

11. van Niekerk S, Human S, Williams J, van Wilpe E, Pretorius M, Swanepoel R, et al. Sindbis and Middelburg old world alphaviruses associated with neurologic disease in horses, South Africa. Emerg Infect Dis. 2015;21:2225-9. https://doi.org/10.3201/eid2112.150132

12. Kokernot RH, Smithburn KC, Weinbren MP. Neutralizing antibodies to arthropod-borne viruses in human beings and animals in the Union of South Africa. J Immunol. 1956;77:313-23.

13. Kokernot RH, De Meillon B, Paterson HE, Heymann CS, Smithburn KC. Middelburg virus; a hitherto unknown agent isolated from Aedes mosquitoes during an epizootic in sheep in the eastern Cape Province. S Afr J Med Sci. 1957;22:145-53.

14. Attoui H, Sailleau C, Mohd Jaafar F, Belhouchet M, Biagini P, Cantaloube JF, et al. Complete nucleotide sequence of Middelburg virus, isolated from the spleen of a horse with severe clinical disease in Zimbabwe. J Gen Virol. 2007;88:3078-88. https:/ / doi.org/10.1099/vir.0.83076-0

15. Smithburn KC, Kokernot RH, Heymann CS, Weinbren MP, Zentkowsky D. Neutralizing antibodies for certain viruses in the sera of human beings residing in northern Natal. S Afr Med J. 1959;33:555-61.

16. Kokernot RH, Smithburn KC, Kluge E. Neutralizing antibodies against arthropod-borne viruses in the sera of domestic quadrupeds ranging in Tongland, Union of South Africa. Ann Trop Med Parasitol. 1961;55:73-85. https://doi.org/10.1080/00034983.1961.11686021

17. Hubálek Z, Rudolf I, Nowotny N. Arboviruses pathogenic for domestic and wild animals. Adv Virus Res. 2014;89:20175. https:/ / doi.org/10.1016/B978-0-12-800172-1.00005-7

18. Bancroft JD, Gamble M, editors. 2002. Theory and practice of histological techniques. Edinburgh: Churchill Livingstone; 2002.

19. Zaayman D, Human S, Venter M. A highly sensitive method for the detection and genotyping of West Nile virus by real-time PCR. J Virol Methods. 2009;157:155-60. https://doi.org/10.1016/j.jviromet.2008.12.014

20. van Niekerk M, Freeman M, Paweska JT, Howell PG, Guthrie AJ, Potgieter AC, et al. Variation in the NS3 gene and protein in South African isolates of bluetongue and equine encephalosis viruses. J Gen Virol. 2003;84:581-90. https://doi.org/10.1099/vir.0.18749-0

21. Van Eeden C, Zaayman D, Venter M. A sensitive nested real-time RT-PCR for the detection of Shuni virus. J Virol Methods. 2014;195:100-5. https://doi.org/10.1016/ j.jviromet.2013.10.008

22. Stamatakis A. RAxML version 8: a tool for phylogenetic analysis and post-analysis of large phylogenies. Bioinformatics. 2014;30:1312-3. https:/ / doi.org/10.1093/bioinformatics/btu033

23. Forrester NL, Palacios G, Tesh RB, Savji N, Guzman H, Sherman M, et al. Genome-scale phylogeny of the alphavirus 
genus suggests a marine origin. J Virol. 2012;86:2729-38. https://doi.org/10.1128/JVI.05591-11

24. Powers AM, Brault AC, Shirako Y, Strauss EG, Kang W, Strauss JH, et al. Evolutionary relationships and systematics of the alphaviruses. J Virol. 2001;75:10118-31.

https://doi.org/10.1128/JVI.75.21.10118-10131.2001

25. Weaver SC, Kang W, Shirako Y, Rumenapf T, Strauss EG, Strauss JH. Recombinational history and molecular evolution of western equine encephalomyelitis complex alphaviruses. J Virol. 1997;71:613-23. https:/ / doi.org/10.1128/ JVI.71.1.613-623.1997

26. McIntosh B. The epidemiology of arthropod-borne viruses in southern Africa. Pretoria (South Africa): University of Pretoria; 1980.

27. Adams AP, Aronson JF, Tardif SD, Patterson JL, Brasky KM, Geiger R, et al. Common marmosets (Callithrix jacchus) as a nonhuman primate model to assess the virulence of eastern equine encephalitis virus strains. J Virol. 2008;82:9035-42. https:/ / doi.org/10.1128/JVI.00674-08
28. de Novaes Oliveira R, Iamamoto K, Silva ML, Achkar SM, Castilho JG, Ono ED, et al. Eastern equine encephalitis cases among horses in Brazil between 2005 and 2009. Arch Virol. 2014;159:2615-20. https:/ / doi.org/10.1007/s00705-014-2121-4

29. Bengis RG, Leighton FA, Fischer JR, Artois M, Mörner T, Tate CM. The role of wildlife in emerging and re-emerging zoonoses. Rev Sci Tech. 2004;23:497-511.

30. Lederberg J, Shope RE, Oaks SC Jr. Emerging infections: microbial threats to health in the United States. Washington: National Academies Press; 1992.

31. Morse SS. Factors and determinants of disease emergence. Rev Sci Tech. 2004;23:443-51. https://doi.org/10.20506/ rst.23.2.1494

Address for correspondence: Marietjie Venter, Faculty of Health Sciences, Department of Medical Virology, University of Pretoria, PO Box 2034, Pretoria 0001, South Africa;

email: marietjie.venter@up.ac.za

\section{EID Podcast:}

\section{Developing Biological Reference Materials to Prepare for Epidemics}

Having standard biological reference materials, such as antigens and antibodies, is crucial for developing comparable research across international institutions. However, the process of developing a standard can be long and difficult.

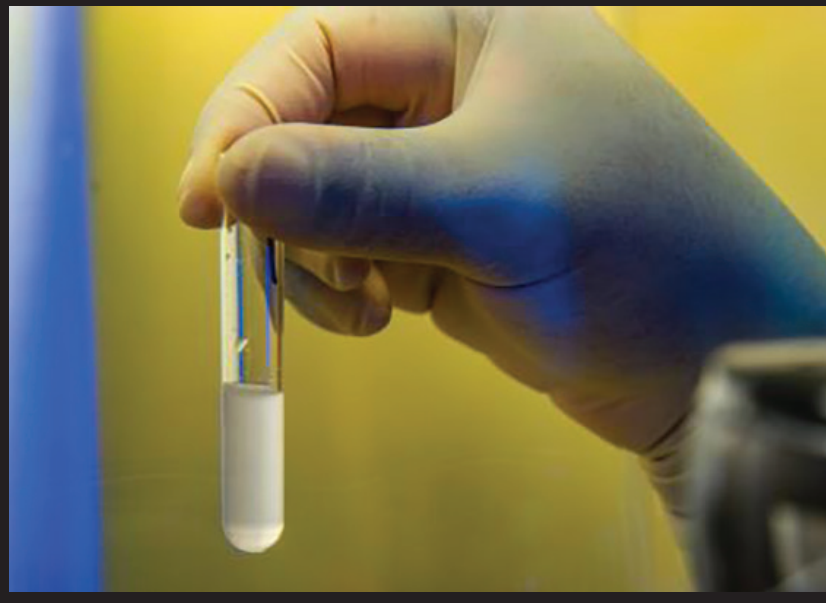

In this EID podcast from February 2019, Dr. Tommy Rampling, a clinician and academic fellow at the Hospital for Tropical Diseases and University College in London, explains the intricacies behind the development and distribution of biological reference materials.

\section{Visit our website to listen:}

\section{https://tools.cdc.gov/medialibrary/index.aspx\#/ media/id/397260}

